\title{
中职校学前教育专业特色班集体创建的实践探究
}

\author{
吴裕美 \\ 江苏省南通中等专业学校 \\ DOI:10.32629/er.v3i4.2648
}

[摘 要] 本文针对我国中职学校中的特色班集体进行了探究,对其专业特色展开了调查分析,并在最后做出了总结性的实践措施建议,希望能够 对相关教育机构起到帮助作用和借鉴意义。

[关键词] 中职校; 特色班级文化; 发展途径

学校是有各个班级组成的, 而班级又是一个学生团体, 为学生发扬个 性设置的场所, 能够帮助学生将个体行为发展的更具社会化。在一般情况 下, 学生所具有的道德品质是在不断的与人交往和活动中养成的。越是丰 富多彩的集体活动, 就越能够成为学生德育的教学载体。就我国而言, 创建 特色班级, 目的是在保留学生运动量的前提下, 充分结合教育知识点, 将学 生的特长和目标进行再一次的培育, 提高对学生的德育教育水平。其中, 音乐教育是一项非常重要的工作, 它可以丰富校园的教学文化氛围、提高 学生们的文化品味、同时还能够有效的处理音乐教育体系的针对性问题, 将学生的主动性和实效性充分挖掘出来, 使学生的音乐教育工作能够得到 进一步保证。

\section{1 特色班集体的内涵与目的}

1. 1 特色班集体的内涵

想要建立起一个具有特色的优秀班集体, 首先要做到的是拥有共同的 一致性、合理性, 要求集体拥有更高的凝聚力, 班级内的学生共同体能够有 一个共同为之奋斗的追求目标。本文强调的 “特色班级” 和以往的 “班级 特色”具有不同的实际意义, 特色班级是指以班级作为基点, 内部的全体学 生能够组成一个多彩的立体形式, 进而产生更强的约束力, 做到 “人无我 有” 的班级状态 ${ }^{[1]}$ 。这样的特色班级往往具有更加强烈的集体风格, 班级 内的各个成员大多具有一致的追求目标, 能够帮助班级的文化内涵和精神 内涵得到进一步的发展。创造出这样更具内涵的班集体, 可以使学生的团 队意识更强, 尤其是在音乐方面, 有各种不同的乐器相配合, 演奏出来的音 乐往往比单一乐器更具魅力。基于上述情况, 在中职校开展学前特色班 集体的建设是非常有必要的, 而音乐又是一种极具优势的文化传承, 将 两者进行有效的、科学的结合, 能够帮助学生养成更加符合社会发展的 个人本领。

\section{2 特色班集体创建的目的}

对于创建特色班集体的目的而言, 是社会各界的教育机构对学生自身 的个性化发展提出的要求, 从根本上改变过去的毫无特色的班级集体, 避 免曾经的学生生活缺少色彩的在校经历, 为学生的在校生活添加更多的乐 趣, 从而丰富他们人生中的学习经历, 为其保留一段良好的求学回忆。与此 同时, 在这样的校园环境中培养出来的学生往往具有更强的环境适应能力 和更强的专业程度, 可以为社会输送更多的实用型人才。在这样的情况下, 已知特色班集体的创建能够满足多方面的实际需求和学生的个人需要, 同 时特色班集体还能对学校的教学工作起到促进作用. 所以, 在校园内进行 特色班集体的组织活动是非常有必要的。而音乐就是一种能够将班级内的 学生聚拢到一起的介质, 因为其自身的魅力和对团队的需要, 能够是班集 体的凝聚力更上一个台阶, 也能够使班集体的音乐特色氛围更加浓厚。在这 样的环境下, 创建更多的相关活动, 能够有效提升学生的综合素质, 从而让 校园的德育工作更加欣欣向荣, 将学校的管理水平和办学品位再度拉高。

\section{2 职校学前教育专业特色班集体创建的重要性}

2.1 符合整个班级和学生未来发展的需求

打造校园特色班集体属于班级发展阶段的重要发展途径之一, 还能够 为学生们提供全新的成长环境。在一个班集体中, 内部的各个学生都会具 备不同的文化素养、性格特点和兴趣爱好, 正是因为上述的这些差异会明 显的存在, 所以在这个班集体的生活中会发生各式各样的问题。针对这一 特点, 学校要积极采取应对的措施, 用以保证每个学生个体都能够更好的 融入到集体生活之中, 让特色班集体变的更加具有存在价值, 也更有实际 意义, 所以, 特色班集体的班主任就需要全力完成特色班集体的打造计划。 在此之外, 学校打造特色班集体的主要目的就是为学生创造出更加优越的 发展空间和成长环境。一个足够优秀的特色班集体对日后的学生发展起到 促进作用是一件必然的事情, 这也是人们公认的一个社会规律。

学校创建特色班集体建设活动, 进一步提高学生的发展意识, 增强学 生自身的团队荣誉感, 优化学生之间的协作意识。在上述过程中, 学生自身 也能够将社交沟通能力、团结协作能力和自我表达能力等进行有效的锻炼, 而上述的这些能力都属于在社会上发展的必备能力。

\section{2 是提高教育教学质量的需要}

无论是种植花草树木, 还是悬挂宣传标语, 都需要从审美的方向出发, 进行教育的深入化研究, 然后在从研究结果中找到那些具有潜移默化性质 的育人功能。在班级的日常学习生活中, 对于班集体的管理工作和教学任 务来说, 创建出更具特色的班集体会产生强劲的促进作用, 更是班级文化 建设工作的重要组成结构。身为一种比较特殊的教学模式, 会在整个的教 育教学阶段起到润物无声的作用, 对于学校的教学质量来说是一项至关重 要的工作环节。

提升教学质量, 不仅仅是要加强教学水平, 还要注意学生的接受能力 和接受水平, 注意学生在教学活动中的主体地位, 加强学生在教学活动中 的参与感, 为其打造更加浓郁的学习氛围, 创造出更加有益身心健康的校 园环境, 这些工作都能够使学生的学习效果变的更好, 进而提升学校的实 际教学质量。

2.3 符合中职院校班主任自身发展的需求

对于中职学校的班主任而言, 其主要是在特色班集体的创建活动中担 当引导者和指导者, 同时也属于特色班集体发展建设的主要核心成员。学 生的自身发展情况、班级的管理情况都和班主任的工作有着紧密的联系。

作为班主任, 最大的事业成就感就是自己的学生能够 “出类拔萃”, 并且让班级的整体文化水平能够更上一个台阶, 出现更多的高知识水平人 才。因此, 建设起环境氛围更加良好的特色班集体属于一项学校班主任在 发展过程中的必然追求之一, 更是一项伴随着机遇的全新挑战。

\section{3 中职校学前教育专业特色班集体创建的实践措施}

3. 1 明确特色班级文化创建的思想核心 
班级思想文化具有持久的、内在的优势, 并且具有不可被模仿或者替 代特征。正确的思想文化能够使一个班级获得前进的动力和方向, 极具引 导价值。在学前教育的音乐教学方面, 要坚持把音乐教学工放到主要位置 上来, 保证学前教育目的的统一性, 确保学生能够得到更加实际的培育和 训练, 更好的掌握音乐相关知识, 完善自身艺术水准, 强化对于音乐知识的 认知水平。

在创办特色音乐班集体的活动中, 要注意时刻围绕核心思想, 将音乐 贯彻落实到具体的活动流程中, 使学生能够全程体会到音乐的鬼力, 从而 培养学生对于音乐方面的好感度。

3. 2 开展具有特色的专业训练活动

将音乐作为活动背景, 积极的开展更多的专业性质的训练, 可以使学 生获得更好的音乐体验 ${ }^{[2]}$ 。因为学生会受到周围环境的影响, 在音乐氛围 极其浓郁的情况下, 学生的音乐感知能力和音乐鉴赏水平也会发生潜移默 化的提升, 进而增强学生对于音乐教育教学的各方面发展。例如, 将音乐教 学特色融入到具体的实践活动中, 开展 “天籁之声” 竞赛, 设置相应的荣誉 奖励和物质奖励, 能够充分调动学生的参与性, 进一步动员学生的积极性, 使得比赛更具教育意义, 让学生充分体会音乐的魅力。针对学生个体之 间存在的差异性, 特色班集体的训练活动要提高对活动制度工作的重视, 在尊重学生个性化的同时展开训练效果更佳的专业活动。例如，“音乐 特色班集体” 的建立, 学校需要针对不同的音乐特点进行详细的处理和解 决方案。

\section{3 重视学风班风建设}

学校创建特色班集体的最终目的并不是走形式和赶潮流, 而是要将学 校的制度建设作为建设基础, 在这样的状态下进行班风、学风的建设工作。 同事还要通过班集体开展的各项训练活动来促进特色班集体的发展, 引导 学生从细节入手、从小事入手, 用此来培养学生的生活习惯和学习习惯。 这样的学校教育制度能够更加直接的对在校学生产生影响, 对在校师生的 学习和生活都具有积极的促进作用, 体现出的作用也更加明显。

一个学校的学风和班风会对这个学校的教学工作产生重要影响, 因为 学生在教学中的主体地位, 其主观态度在很大程度上决定了教学质量的高 低。基于上述内容, 学校更应该构建起更加科学的教育制度, 提高对班风和 学风的建设, 确保学生能够获得更加优异的校园环境 ${ }^{[3]}$ 。使在校的全体师 生都能够在这样的情况下开展正常的学习生活, 为师生打造共同的音乐学 习环境, 将老师和学生融入到一个团体之中, 更好的消除传统的师生矛盾, 拉近师生之间的关系, 做到教学增长, 从而为学校的教学质量做出保障。

3. 4 树立学生的主体地位

在校园教育和班级管理方面, 在校学生一直处于主体地位, 学校的各 个班主任要树立以学生为主体的教学观念。在特色班集体的组织活动中亦 是如此, 站在学生的角度出发, 以学生的眼光看待问题, 一切教学活动都是
为了帮助学生获得更好的发展, 为其在日后的成长提供更坚实的基础。在 创建特色班集体活动的过程中, 需要积极动员全员参与工作, 做到人人都 能够为班集体的发展和建设做出贡献, 进而建立起一个更加完整的、正确 的发展观念, 将班集体从真正意义上发展成更适合学生发展的舞台, 使学 生能够意识到自己是特色班集体发展的主人。

学校提高对学前教育过程中的特色班集体发展重视程度,才可以有效 的推动校园特色班集体的发展进程。尤其是在音乐教育方面, 培养学生的 音乐感知, 使其能够爱上音乐, 更加彻底的投入到对音乐教育之中, 这样能 够将校园文化发展的精彩纷呈, 帮助学生养成更加健康的人格, 有助于学 生在日后的自主发展。

\section{5 开展富有特色的主题教育活动}

在瑞士, 曾经有一位著名的音乐教育学家提出过这样一个观点: 音乐 的主要来源就是人们产生的情感, 一般情况下, 人的自身情感会由其肢体 动作进行表达。在中职学校工作的教师, 要充分的认识到这一点, 将学前教 育落实到实处, 充分掌握好与特色班级体之间的连接桥梁, 将两者进行更 好的融合互动, 让特色班集体更具实际意义。

在正常情况下, 学前教育结构中的女生占比较大, 对于歌舞方面的偏 爱程度更高, 在这样的情况下, 积极开展特色班集体建设工作就能够起到 水到渠成的效果, 将音乐的重要性加以详细的说明, 在此之后, 将学生对于 音乐的兴趣和教学活动相结合, 打造 “音乐特色班集体”。音乐属于学前教 育阶段的必修课程, 同时也是学生日后在社会上发展的基础技能之一, 可 以让学生掌握一项过人的社交技能, 从而更好的融入到社会团体之中。

音乐还能够培养学生的艺术鉴赏能力, 长期处于音乐环境的熏陶下, 能够将学生的审美意识提高到另一个水准, 还可以增强学生的语言表达能 力和实际写作能力, 拥有更高的文化素养和文化底蕴。

\section{4 结语}

综上所述, 在中职学校教育教学体系中, 学前教育具有特殊的重要性, 尤其是在开展特色班集体建设方面, 会对在校学生的学习和生活起到帮助 作用, 促进学生的集体荣誉感和团队协作能力。而在学校开展音乐方面的 艺术教育活动, 能够为学生创造更加良好的学习氛围和生活氛围, 促进学 校教学质量的提高, 提升学生对音乐的认知高度, 为学生在音乐方面打下 更加坚实的基础。

[参考文献]

[1]杨天月.浅谈如何提升中职学校学前教育专业——钢琴课的效率 性及应用性[J].明日风尚,2018(18):127.

[2]于春红.中职学校班集体建设和班主任工作艺术的点滴探析[J].新 教育时代电子杂志:教师版,2018(12):271。

[3]赵佳,曹红玲.中职院校学前教育专业人才培养策略探究-一基于能 力素质模型的分析视角 [J].河南教育:幼教,2019(4):3-7. 